\title{
Swaziland's Traditional Birth Attendants Survey
}

\author{
Lech M.M'. and Mngadi P.T ${ }^{2}$.
}

\begin{abstract}
The Traditional Birth Attendants (TBAs) Survey in Swaziland was undertaken between March 27th 1996 and April 8th 1996. The objective of the survey was to generate reliable information regarding activities of TBAs in Swaziland. The survey was conducted in 25 Chiefdoms sampled out of a total of 206 Chiefdoms registered in Swaziland. The total number of sampled respondents in the 25 Chiefdoms was 721 . From the survey, it is estimated that there were probably 3000 TBAs in the country, and in the majority of cases such TBAs would be a 51-year old woman who herself had delivered six children and had worked as a TBA for at least 10 years. Between 9,000 and 12,000 deliveries are estimated to take place out of health facilities. Of these many, nearly $43.5 \%$ are assisted by "TBAs"; $16.3 \%$ of woman interviewed deliver relative/family member and $15.1 \%$ are assisted by friends/neighbours, etc. Some of TBAs carry out procedures which are considered to be potentially harmful. Nearly $30 \%$ of TBAs have administered herbs; $45 \%$ attend to abnormal deliveries (breech and multiple pregnancies); $26.7 \%$ re-use their cord cutting tools and in the case of haemorrhage $23.4 \%$ do manual procedures within reproductive tract of delivering women. (Afr J Reprod Health 2005; 9[3]:137-147)
\end{abstract}

\section{RÉSUMÉ}

Enquête des sages-femmes traditionnelles du Swaziland L'enquête des sages-femmes traditionnelles (SFT) au Swaziland a été menée entre le 27 mars 1996 et avril 1996. L'enquête avait pour but de fournir des renseignements sûrs à l'égard des activités des SFTs au Swaziland. Cette enquête a été menée auprès de 25 chefs-lieux échantillonnés parmi 206 chefs-lieux enregistrés au Swaziland. Au total, 721 répondants ont été échantillonnés dans les 25 chefs-lieux. A partir de cette enquête il est estimé qu'il y a probablement 3000 SFTs dans le pays et dans la plupart des cas, telles SFTs seraient des femmes de 51 ans qui, elles-mêmes, ont accouché six enfants et ont travaillé comme SFTs pendant au moins 10 ans. On estime qu'entre 9000 et 12000 accouchements ont eu lieu en dehors des établissements de santé. De ce chiffre, presque $43,5 \%$ sont aidées par des membres de famille et 15,1\% sont aidées par des amies et des voisines etc. Certaines SFTs suivent des procédures jugées néfastes. Presque 30\% des SFTs ont administré des herbes; $45 \%$ s'occupent d'accouchements anormaux (du siège et des multiples grossesses); $26,7 \%$ se servent à nouveau de leur outils destinés à couper les cordons alors que quand il s'agit de l'hémorragie, 23,4\% emploient des procédés manuels à l'intérieur de faisceaux de reproduction des femmes en train d'acchoucher. (Rev Afr Santé Reprod 2005; 9[3]:137-147)

KEY Words: Home delivery, Traditional medicine, Africa, Safe motherhood, Maternal mortality.

${ }^{1}$ Director of Fertility and Sterility Research Center, 2/4/6 Lucka Str., 00-845 Warsaw, Poland, e-mail: medardlech@poczta.onet.pl Patricia Thuli Mngadi DN, M.Sc. ${ }^{2}$ Faculty of Health Science, University of Swaziland, Mbabane, Swaziland

Correspondence: Medard M. Lech MD, PhD - Director of Fertility and Sterility Research Center, 2/4 / 6 Lucka Str., 00-845 Warsaw, Poland, e-mail: medardlech@poczta.onet.pl 
138 African Journal of Reproductive Health

\section{Introduction}

Maternal mortality is not only one of the health indicators used in the assessment of health-care and socio-economic development of a country but also a major tragedy for the family and children of the deceased mother. In part, this is because the death of the mother negatively affects the future prospect of her children. The death of a mother also means the loss of the primary caretaker and often the main provider of family needs. Furthermore, maternal deaths worldwide, are known to significantly increase the likelihood of deaths of newborns and other smaller children.

In developing countries maternal morality is reckoned to be a hundred times higher than in developed countries ${ }^{(1)}$. It is reported that for every 23rd woman who dies, complications of pregnancy, childbirth or the puerperium are responsible. Maternal mortality rate in Africa is estimated to be 640 per 100,000 live births. In Europe this rate do not exceed 10 per 100,000 live births. The principal causes of maternal deaths in developing countries are: abortions, haemorrhage, toxemia, obstructed labour and infections.

Swaziland (app. 1,000,000 inhabitants) is a small, mountainous country situated in the southeastern part of $\mathrm{Africa}^{(2)}$. In Swaziland, estimation of maternal deaths has proved difficult. Till now, it was based on hospital records. As of 1990, it was estimated to be around 110-130 per 100,000 live births ${ }^{(3,4,5)}$, current rate being quoted is believed to be a gross underestimate; the "out of hospital" birth rate is considerably high. Probably only $56 \%$ of all births in Swaziland take place in health facilities and the remainder at home, without the care of qualified medical staff.

In 1980, Swaziland carried out two separate surveys ${ }^{(6,7)}$ basically to determine the existence of Traditional Birth Attendants (TBA). Little is know about the first study. The second survey was designed to get into greater depth. It was indeed during this study that what was formerly know as "unattended births" were, in fact births attended by TBA.

From the 1988 Family Health survey ${ }^{(0)}$ it was revealed that as much as $38 \%$ of deliveries were actually assisted by TBA and grandmothers (Gogos). Approximately 7\% of deliveries were not attended by anyone at all. Indeed, when these figures are projected for the general population ${ }^{(4)}$, the result is that more than 12,000 deliveries in Swaziland in 1988 were attended by TBAs and Gogos. Currently, there is no reliable information on the number and distribution of TBAs in Swaziland. It is possible that the situation in Swaziland could be similar to one reflected in a comprehensive study carried out in Botswana in $1985^{(8)}$. If that were to be true, then it is possible to assume that one T.B.A. in Swaziland attends to approximately 5-6 deliveries per annum and that most probably approximately 2,000 women are practicing as TBA in the country: mostly in the rural areas.

In the Botswana Study ${ }^{(8)}$, these women are mostly little-educated and have never received any training in midwifery. All they know, is that they inherited from other TBA and or learned from their own deliveries and practice. Looking from a different viewpoint it was also discovered that TBA carried out unsafe maternity procedures which are often associated with loss of lives of mothers and newborns. In other words, and on account of the Botswana experience, it is probably reasonable to assume that unsafe procedures also do happen in Swaziland. If so, they are probably the ones responsible for the high maternal mortality in rural areas.

The Government of Swaziland identifies maternal mortality levels as unacceptably high and wants them reduced by half by the year $2005^{(3)}$. To be able to achieve this aim it would require intensive mobilisation of financial and all human resources involved in the care of pregnant and delivering women. This would be to enable more deliveries to be performed in fully-equipped and fully-staffed hospitals. It would also mean that many woman delivering out of health facilities would receive more qualified help; that deliveries

African Journal of Reproductive Health Vol. 9 No.3 December 2005 
will be performed in clean and safe environments.

\section{Problem statement}

Meaningful progress in the Safe Motherhood Initiative can only be realised when there is a corresponding improvement in the formal health sector as well as the informal or traditional midwifery system currently being promoted by TBA. In fact, it is against this background that the Ministry of Health and Social Welfare felt it necessary, prior to implementation of methods designed to improve services provided by TBA, to assess the present strengthens and weaknesses of the "home delivery system".

\section{Objectives}

The overall objective of the survey was to generate reliable information on maternity care being provided outside the modern health-care facilities in Swaziland. The specific objectives were:

(a) To conduct a census of Traditional Birth Attendants in the sample survey areas of Swaziland.

(b) To determine the socio-economic characteristics of TBA; the number of deliveries conducted by TBA; the relationship between TBA and the women delivered by them.

(c) To assess the knowledge, practice, attitudes, scope and concepts of work of TBA. (d) To determine the attitude of the general public towards TBA and their activities.

(e) To assess the current functional relationship between TBA and the formal healthcare system.

\section{Methods}

Three different sets of previously designed and pre-tested questionnaires were fielded between March 27th and April 8th 1996 to three different population groups in the Swazi Community. The three population groups were the Community Leaders, Traditional Birth Attendants and mothers who had delivered at home 3 months prior to the survey.

The interviewees had been drawn from 25 randomly selected Chiefdoms out of a total of 206 that are registered with the Deputy Prime Minister's Office (DPM's). This is approximately $12 \%$ representation of the total chiefdom population (see Table 1).

The survey instruments were fielded by 4 teams (i.e. one per region), each comprising of 3-4 people or interviewers who had previously undergone a two-day training in their use. The interviewers were, in turn and on the spot and or verify/check completion of the questionnaires.

In order to locate the Chiefs and other survey respondents, Rural Health Motivators (RHMs) residing in the area had to be identified and asked to help. Table 2 below shows the total number of potential respondents and those actually

Table 1 Population and chiefdom distribution by region and sampling*

\begin{tabular}{|l|c|c|c|c|}
\hline Region & \multicolumn{2}{|c|}{ Estimated total population in 1995 } & \multicolumn{2}{c|}{ Total number of Chiefdoms, 1995 } \\
\cline { 2 - 5 } & in the reg10n & 1n sampled Chiefdom & 1n the region & 1n the sample group \\
Hhohho & 232,922 & 29,342 & 61 & 7 \\
Lubombo & 218,501 & 38,133 & 22 & 5 \\
Manzini & 201,981 & 20,222 & 46 & 5 \\
Shiselweni & 257,340 & 36,846 & 77 & 25 \\
\hline TOTAL & 910,744 & 124,543 & 206 & 8 \\
\hline
\end{tabular}

* Source: Central Statistics Office, Swaziland Population Projections and DPM's Office.

African Journal of Reproductive Health Vol. 9 No.3 December 2005 
140 African Journal of Reproductive Health interviewed.

Community Leaders and Rural Health Motivators were to be asked about their status in the community; about distances from the nearest health facility to the centre of the Chiefdom and also about their relations with TBAs. They were further to be asked to identify TBAs and mothers in their respective communities.

TBAs as a study group were to be asked about their socio-economic status; the practice and performance of home deliveries. They also had to be asked about their relationship with the formal health sector; about their work as advisors to pregnant (delivering) women.

Questions designed for mothers focused on

(a) their social and personnel status;

(b) the distance from the nearest health facility;

(c) the history of their last pregnancy, delivery and puerperium; and

(d) on the use of traditional methods of care for themselves and their babies.

Interviews were conducted with due regard for privacy and convenience. Sensitive questions were reserved until the end of the interview.

At the conclusions of the survey, all data was, again subjected to scrutiny for completeness and consistency. Data processing, data entry, data checking and editing was done by the Statistics Unit team of the Ministry of Health, using the EPI Info Software Programme Package.

Apart from possible sampling errors, misinterpretations and interviewers' errors, other limitations of the survey included difficulties in tracing mothers who had delivered 3 months prior to the study; some TBAs and Community Leaders refusing to co-operate, stated that they wanted to be paid for the interviews.

\section{Results}

\section{Interviews with Community Representatives/}

\section{Leaders}

The purpose of holding interviews with Community Leaders and other representatives was basically to determine (a) if they were aware or knew of someone practicing as a TBA and (b) if aware, what relationship existed between the community and the TBAs themselves.

One hundred and seventy-three people in this category were interviewed. Formal Community Leaders (i.e. Chiefs) and their nearest co-workers accounted for $32.4 \%$ of all respondents. Rural Health Motivators, on the other hand, accounted for $64.7 \%$ of all respondents. Some RHMs were also found to be involved on other

Table 2. Total Respondents and those actually interviewed.

\begin{tabular}{llll}
\hline Target group & $\begin{array}{l}\text { Total number of } \\
\text { respondents in sampled } \\
\text { Chiefdoms identified }\end{array}$ & $\begin{array}{l}\text { Respondents actually } \\
\text { interviewed }\end{array}$ & interviewed \\
\hline Community Leaders/RHMs & 173 & 173 & $100 \%$ \\
Mothers & 182 & 154 & $84.6 \%$ \\
TBAs & 367 & 251 & $69.9 \%$ \\
\hline TOTAL & 721 & 588 & $81.5 \%$ \\
\hline
\end{tabular}


official functions other than those of being RHMs. Indeed, which is why some of them had to be included in the group of interviewees.

Nearly $82.0 \%$ of respondents knew of some people serving as TBA in their communities; $11.0 \%$ of respondents also confirmed the involvement of Rural Health Motivators in home deliveries. In some communities, some $30.0 \%$ of respondents knew of at least two people who conduct home deliveries. In others, as represented by $22.6 \%$ respondents, three or more people were known to be performing home deliveries in the community.

Table 3, shows the breakdown of the 173 respondents who knew or did not know of people who conduct home deliveries in the sampled Chiefdoms, by administrative regions of Swaziland.

On the relationship between the community and TBAs: $52.8 \%$ of respondents - Community Leaders - reported that they support the work of TBAs in the community; mostly by providing or helping obtain transport in case of emergencies.

A well-established and functioning information transfer between Traditional Birth Attendants and Community Leaders and/or "Births, Deaths and Marriages registration Offices" or health facilities could be a very important source of obtaining information on home deliveries in Swaziland. And, in fact, because of this reason an indirect attempt was made to check the functioning status of the system. Interviewers had to ask Community Leaders if they were receiving any information from TBAs.

Approximately one-third (34.5\%) of respondents, mostly Rural Health Motivators, admitted of receiving information from TBAs; $14.9 \%$ of others record stillbirths and abortions.

While performing their duties some RHMs do also record births and deaths in their Monthly Reports forms routinely sent to the Ministry of Health. All together, $50.0 \%$ of respondents reported the existence of "demographic information" transfer from the community or Rural Health Motivators to the $\mathrm{MOH}$.

Only $2.0 \%$ of Community Leaders/Health Workers also reported the existence of some linkage between the community and the BirthsDeaths-Marriage registrations Offices.

\section{Interviews with mothers who delivered the last child outside of a health facility}

This part of the study sought to determine the social characteristics of women who deliver at home, why they do so and by whom they are delivered. It was also to check postpartum practices. In all these aspects, the 4 teams of inter-

Table 3. Number of persons known (by interviewed persons) to be prasticing home deliveries in communities.

\begin{tabular}{lccccc}
\hline Region & None & One & Two & 3 or More & Total \\
\hline Hhohho & 9 & 19 & 12 & 8 & 48 \\
Lubombo & 10 & 17 & 12 & 6 & 45 \\
Manzini & 14 & 10 & 5 & 7 & 36 \\
Shiselweni & 3 & 19 & 12 & 10 & 44 \\
\hline TOTAL & 36 & 65 & 41 & 31 & 173 \\
\hline
\end{tabular}

African Journal of Reproductive Health Vol. 9 No.3 December 2005 
142 African Journal of Reproductive Health

viewers were able to interview 154 mothers who had delivered their children at home during the period of 25th December 1994 to 25th March 1995.

\section{Social Characteristics}

The average respondent was: an unemployed housewife, 27.9 years old; living in an extended family and already in the care of four children. Nearly $32 \%$ of the respondents were uneducated and $44.5 \%$ had finished their primary education.

\section{Proximity to health facility}

One other interesting outcome of this survey is that respondents reported that the distance between their respective homes and the nearest health facility was not very long. On average, it took them only 40-45 minutes to reach a health facility. This was further confirmed by a group of "Community Leaders" (Table 4).

\section{Clinical Attendant with last delivery}

During the last pregnancy, 82.5\% of the 154 respondents were seen by midwives in health facilities; 11.0\% were seen by Traditional Birth Attendants and other Community Health
Workers and $6.5 \%$ of respondents delivered on their own or without help of any one. Of all those women who delivered in homesteads, reported to have delivered in their respective houses; $2.6 \%$ delivered in houses of Traditional Birth Attendants. Nearly 45\% of respondents reported to have previously delivered their babies at home, three and more times.

From the Table 5, it is clear that a home delivery is not only a preoccupation of TBAs $(43.5 \%)$ but also and significantly a family affair $(23.1 \%)$.

\section{Reasons for home delivery}

One other important aspect for conducting this survey was to determine the reasons why mothers preferred or delivered at home and not in health facilities.

In the case of $17.3 \%$ respondents: labour was quick and there was no time even to think of going to a health facility. Forty-four percent of respondents consciously chose to deliver at home under the care of an "always available TBA". Some other respondents (9.3\%) reported

Table 4 The distance between homesteads of respondents and the nearest health facility (measured in terms of time it takes to reach a health facility and the method of transportation).

\begin{tabular}{lccc}
\hline & Mothers' Opinion & $\begin{array}{c}\text { Community Leaders' } \\
\text { Opinion }\end{array}$ \\
\hline $\begin{array}{l}\text { Distance as measured by } \\
\text { time (in minutes) }\end{array}$ & $0-30$ & $38.3 \%$ & $37.0 \%$ \\
& $31-60$ & $32.5 \%$ & $31.2 \%$ \\
& & $16.2 \%$ & $15.0 \%$ \\
Way of transport & Walking & $35.7 \%$ & $59.5 \%$ \\
& By Bus & $44.2 \%$ & $37.6 \%$ \\
& Walk and bus & $19.5 \%$ & - \\
& Other & $0.6 \%$ & $2.9 \%$ \\
\hline
\end{tabular}


Table 5. Person who attended the delivery of mothers who delivered at home.

\begin{tabular}{lcc}
\hline Person who attended last delivery & Frequency & Percentages \\
\hline TBA & 64 & 43.5 \\
RHM & 18 & 12.4 \\
Mother/Mother in Law & 23 & 15.6 \\
Sister & 5 & 3.4 \\
Midwife & 3 & 2.0 \\
Grandmother and other relatives & 6 & 4.1 \\
Friends/neighbors & 4 & 2.7 \\
On their own/self & 24 & 16.3 \\
\hline Total woman delivered at home & 147 & 100.0 \\
\hline
\end{tabular}

to have deliberately decided to deliver on their own due to a "more relaxing atmosphere in home surroundings".

Other factors reported to have contributed to the choice of a "home delivery" were: nonavailability of transport; lack of money for paying the hospital bill; and bad experience from a previous delivery in health facilities. Mothers were further asked what would be their preferred place of delivery if they were to become pregnant again. Nearly half said they would still opt for a home delivery and the other half would go to a health facility.

\section{Postpartum Care}

Nearly 4 out of 5 TBAs (82.8\%) advise mothers delivered by them to go to the Hospital or Clinic for check-up. A good $61 \%$ of such women take their newborns to the clinic for immunization within 3 months of delivery. Some $18.8 \%$ of mothers use traditional methods of "immunization" or protecting the child.

\section{Interviewes with Traditional Birth Attendants (TBAs)}

This part of the report represents a summary of some basic characteristics of TBAs in Swaziland. Two hundred and fifty-one TBAs were interviewed. Their distribution is as shown in Table 6.

\section{General Profile of TBAs}

On average a TBA in Swaziland is a 51-year old woman with approximately 6 children of her own. She would have completed the first four years of primary school; possesses a TV set or radio and would have practised as a TBA for more than 10 years. While $31.0 \%$ of TBAs use their own homes as the place for attending to deliveries, $69.0 \%$ attend to deliveries in the homes of their clients. On another note, $28.0 \%$ of TBAs attend to deliveries of their relatives only; the rest $(72 \%)$ attend to both: their relatives and other women.

TBAs on average, had attended to 3-4 deliveries during the preceding 12 months. The actual range was $0-20$ deliveries. More specifically $82.9 \%$ of TBAs attended 0-4 deliveries; $11.5 \%$ : 5-9 deliveries and 5.6\%: 10 or more deliveries. Some of the respondents $(21.5 \%)$, perhaps due to old age and disabilities, have already stopped conducting deliveries. They concentrate on giving advice to mothers and other less experienced TBAs.

In the majority of Chiefdoms TBAs also knew that there were some other people participating in home deliveries. $76.0 \%$ of respondents indicated that the "other person" was a TBAs; $11,5 \%$ said it was an RHM and $12.0 \%$ some other 
144 African Journal of Reproductive Health

Table 6. Distribution of TBAs interviewed by administrative regions of Swaziland.

\begin{tabular}{lcc}
\hline Region & Frequency & $\mathbf{\%}$ \\
\hline Hhohho & 75 & 29.9 \\
Lubombo & 67 & 26.7 \\
Manzini & 49 & 19.5 \\
Shiselweni & 60 & 23.9 \\
\hline TOTAL & 251 & 100.0 \\
\hline
\end{tabular}

person other than a TBA or RHM.

\section{Midwifery Practice by TBAs}

Table 7 below shows the frequency and situations when herbs are administered to clients by TBAs.

During pregnancy, herbs were given mostly to avoid complications. During labour, this type of treatment was mostly given to experdite labour. $45 \%$ of TBAs also reported to be involved in assisting abnormal and complicated deliveries. Most commonly they attended to breech and multiple deliveries. Further to inquiring about the use of herbs, 3 more questions were fielded with the aim of identifying the nature of: -

(a) advance preparations made by TBAs for conducting deliveries,

(b) clinical procedures normally undertaken during deliveries,

(c) actions taken in case if difficult deliveries and maternity emergencies.

Virtually all TBAs make some preparations before conducting a delivery. Sadly, only $12.7 \%$ of TBAs keep some clean water and soap. Most TBAs prepare in advance some materials for cutting and tying the cord. 18\% of TBAs use medically unacceptable materials such as the reed or pieces of broken bottles to cut the umbilical cord. Nearly $14 \%$ of TBAs keep and use sisal threads and pieces of cloth to tie the umbilical cord.

Squatting during delivery was a preferred position by a significant $36,7 \%$ of TBAs. Less than $25 \%$ of TBAs allowed patients to deliver in the position of their choice. Some $2 \%$ of TBAs were not tying the cord before cutting it; $9.6 \%$ were leaving the cord stump too long or too short. As much as $27.5 \%$ of TBAs were re-using their cutting equipment. $26.7 \%$ of TBAS were not using any kind of dressing for the cord stump and as much as 34\% were using herbs, cow dung, red ochre, soil or ash to cover the cord stump. All these products are known to be potentially harmful to the newborn.

One of the indirect objectives of this survey was to determine how TBAs react confronted with dangerous or life threatening situations during delivery.

Table 7. Use of herbs by TBAs during pregnancy and delivery.

Give Herbs To pregnant patients To delivering patients To patients after delivery of placenta

\begin{tabular}{lccc}
\hline Yes & $27.1 \%$ & $29.4 \%$ & $18.7 \%$ \\
No & $72.9 \%$ & $70.6 \%$ & $81.3 \%$ \\
\hline Total & $100.0 \%$ & $100.0 \%$ & $100.0 \%$ \\
\hline
\end{tabular}


In case of excessive bleeding for instance, $51.8 \%$ of TBAs refer patients to the nearest health facility; $31.5 \%$ of respondents wait until bleeding stops; $10.7 \%$ give herbs.

With retained placenta, $11.0 \%$ of TBAs initially take no action. Others reported to:

(1) "Put a hand into the vagina/uterus and pull the placenta out" - 24.6\%.

(2) "Press the abdomen/uterus" - 23.4\%.

(3) "Refer patients to a health facility" $18.2 \%$.

(4) "Ask mothers to blow an empty bottle" $-16.0 \%$.

(5) "Give herbs" $-2.6 \%$.

In the case of distress of the newborn (i.e. "when the baby fails to cry at birth"), $8.0 \%$ of TBAs initially do nothing. Other TBAs reported to:

(1) "Splash cold water onto the baby" $30.0 \%$.

(2) "Slap the baby" $-28.7 \%$.

(3) "Breathe into the baby" - $11.5 \%$.

(4) "Fan the baby" - 8\%.

Home deliveries attended to by TBAs are considered a very private and personal business. It is only in the case of emergency that TBAs feel there is need to call somebody else to help. TBAs are reported to call:

(1) "Other community members for transport" - 62.7\%,

(2) "Clinic nurse" - in 14.1\% of cases

(3) "Members of the family or nearest neighbour" - in 10.3\%.

(4) "Other TBA or RHM" $-7.0 \%$.

(5) "Community Leader" - $2.1 \%$.

The end of labour and delivery of the baby is not the end of the work of TBAs. Some of them $(33.1 \%)$ perform "traditional immunization". Most of them advise as follows:- 92.7\% of TBAs advise mothers to visit a health facility for postnatal care and immunization, $68.5 \%$ of respondents advice mothers to start breastfeeding immediately after delivery, $57.4 \%$ of TBAs advise mothers on spacing of births of their children; mostly offering modern or natural methods.

Before concluding interviews with TBAs, some more personal questions were administered. These focused on remuneration and the spacing of births. Nearly $12.0 \%$ of TBAs admitted to be receiving some kind of remuneration for their activities.

On child spacing and as it has been shown above, TBAs were advising mothers on birth spacing. Furthermore, $52.6 \%$ of TBAs practised child spacing themselves. About $35.1 \%$ of these TBAs were using natural methods of family planning and $16.3 \%$ of respondents (i.e. TBAs) used modern methods of contraception.

Finally and important among the reasons for conducting this survey was to assess the knowledge and skills of TBAs. The assessment was done and details of the results are discussed elsewhere in this report. In a nutshell, $91.6 \%$ of TBAs are willing and ready to upgrade their knowledge and clinical skills.

\section{Discussion}

One of the interesting findings of this survey was the good accessibility of health facilities for the respondents (Table 4). On average, 69.5\% of respondents reported that it would take at most one hour to reach a health facility; $47.6 \%$ said it was within a walking distance.

These findings correspond very well with those reported in the recently completed "Swaziland Immunization and Diarrhea Baseline Study - March 1995”(9).

From the "Demographic and Housing Survey 1991 " (10), only $59.5 \%$ of the Swaziland population took less than one hour to reach a health facility.

The difference between these two figures 
146 African Journal of Reproductive Health

$(69.5 \%$ and $59.5 \%)$ is rather big and requires an explanation. In the first instance, it is possible that the catchments or operational area of TBAs is/ was much bigger than that of our interviewers.

It is most probable that our interviewers could not get in touch with all the potential respondents especially those living in remote homesteads. This is probably what gives one the impression that health facilities are very accessible in the present survey. In fact, if that were the case then the results of this survey are an over-estimation of what the actual situation is. In other words, the situation could be worse than indicated. Furthermore, it should be noted that easy access to a health facility does not necessarily mean easy access to maternity care.

In addition, it is possible to expect that mothers living in more remote areas are less educated and, therefore, less likely to utilise health facilities and consequently opt for home deliveries. This proposition is, in fact, partly confirmed by $2.6 \%$ of mothers reporting that their last delivery took place in the TBAs home and partly by $31 \%$ of TBAs also admitting to have delivered women in their (TBAs) own houses. The apparent discrepancy in the supporting data $(2.6 \%$ and $31.0 \%)$ is probably due to differences in the catchment areas of the two population groups. It is most likely that the catchment area of the TBAs was much larger than that of interviewers.

This survey has also revealed a higher number of practising TBAs than one had expected (). It has also been shown that the average number of deliveries attended to by TBAs was relatively low and that the existence of professional TBAs in Swaziland needs to be confirmed. For now it appears that a TBA is a person who has been chosen or designated by the family or inhabitants of the nearest homesteads to help with deliveries in the neighbourhood.

The survey has further revealed that $82.5 \%$ of mothers who had delivered "at home" had more or less been regularly seen by midwives in health facilities while they were pregnant. This is interesting and difficult to be believed that such women were not told about the advantages of delivering in health facilities. It is also difficult to believe that all these women who had attended ANC in health facilities had no pregnancy or delivery risk factors. Official statistical data from the Ministry of Health confirm this phenomenon; in the period of 1983-1994 proportion of deliveries in health facilities to total number of livebirths in Swaziland fluctuated between 38\% and $53 \%$

One more factor related to these observations is that nearly $40 \%$ of women who delivered at home was very much convinced or preferred to deliver without any help or at most with the assistance of the closest female relative, e.g. mothers, mothers in law, sisters, etc. The belief or decision to deliver at home seemed to be influenced by socio-cultural factors rather than the distance to the nearest health facility, age or parity of the woman. In other instances, however, the decision to deliver at home was a result of some bad past experience with oneself or a member of the family while giving birth in a health facility. The contrary was also reported whereby women changed their minds in favour of health facility delivery because of past nasty experience while under the care TBAs.

In view of this whole set of observations, it is thus imagined how difficult it would be to change the attitudes of the population in favour of health facility maternity care. Alternatively, it can only be stressed how important and how urgent it is to upgrade the knowledge and skills of TBAs.

The importance of breastfeeding appears to be very well know amongst mothers who deliver at home. Most of them begin breastfeeding immediately after delivery. Only one mother among the respondents initiated feeding of the newborn with herbs "tinsiti".

In seeking to work with and or participate in the training of TBAs, one is urged to understand and acknowledge that TBAs have unquestion- 
able position on their respective communities; they are respected by everybody and their advice are immensely valued by mothers. In remote areas, TBAs may also be the only people who can help mothers with deliveries. Indeed, they may also cause damage. These and many more other reasons point as to why there is need for modern health-care providers to develop a better understanding and cordial working relationship with TBAs.

Better service provided by TBAs also means fewer complications with home deliveries; less work for medical personnel and ultimately safer deliveries for all women in the country and a corresponding reduction in maternal and perinatal morbidity and mortality.

Following a critical analysis of the findings, the set of recommendations have been prepared and submitted to the Ministry of Health and full plan of action was prepared and implemented.

\section{Acknowledgements}

The study was supported by UNFPA (Project SWA/92/POI) and the Ministry of Health of Swaziland.

\section{REFERENCES}

1. Royston E, Armstrong S, Preventing Maternal Deaths, WHO, 1989

2. Swaziland Population Projections 1986-2016, Central Statistics Office, Mbabane, 1987

3. Mother-Child Health and Family Planning System Rapid Evaluation, WHO, Mbabane, 1994

4. Report of the proceedings of the National Maternal and Perinatal Mortality Meetings of Swaziland, Ministry of Health, 1988,

5. Swaziland in Patient Health Information System, 1983-87 Report, SIMET, 1990

6. Swaziland - 1988 - Family Health Survey, Ministry of Health, Mbabane, 1990

7. Traditional Birth Attendants Survey - Swaziland - 1988, personal information.

8. Botswana National Health Bulletin, B.N.H.I. Gaborone, 1985

9. Swaziland Immunization and Diarrhoea Baseline Study, Ministry of Health-UNICEF, Mbabane, 1995

10. Demographic and Housing Survey 1991, Central Statistics Office, Mbabane, 19 